\title{
Development of a Mitochondrial SCAR Marker Related to Susceptibility of Banana (Musa AAA Cavendish) to Fusarium oxysporum f. sp. Cubense Race 4
}

\author{
Fang WANG ${ }^{1}$, Ling XIA ${ }^{1}$, Shun $\mathrm{LV}^{1 *}$, Chunxiang XU ${ }^{2 *}$, Yuqing NIU ${ }^{2}$, \\ Wenqing $\mathrm{LIU}^{1}$, Lisha ZENG ${ }^{1}$, Jiankun $\mathrm{ZHOU}^{1}$, Bei $\mathrm{HU}^{2}$ \\ ${ }^{1}$ Dongguan Banana and Vegetable Institute, 3 Jiye Road, Dongguan 523061, China; 29333689@qq.com; 519716119@qq.com; \\ shunlv@21cn.com (*corresponding author);lwq010101@sina.com;371924298@qq.com;42236266@qq.com \\ ${ }^{2}$ South China Agricultural University, College of Horticulture, 483 Wushan Road, Guangzhou 510642, \\ China; chxxu@scau.edu.cn ("correspondingauthor);2639313268@qq.com;825826663@qq.com
}

\begin{abstract}
The use of resistant cultivars is an effective method for the control of banana (Musa spp.) Fusarium wilt caused by race 4 of Fusarium oxysporum $\mathrm{f}$. sp. cubense (Foc 4 ). However, selection of disease-resistant cultivars requires large-scale field evaluations and is time-consuming. Development of early, reliable, and reproducible selection strategies can speed up this process. Sequence characterized amplified region (SCAR) markers have been widely employed in the resistant breeding of many crops. However, to date, there have been no reports about the presence of plant disease resistance-related SCAR markers in mitochondrial genome yet, which also plays a very important role in plant defenses. In the present study, a sequence-related amplified polymorphism (SRAP) marker, a specific fragment of $829 \mathrm{bp}$, was identified. This fragment could be amplified from Foc4-susceptible but not from the resistant cultivars. It was located in banana mitochondrial genome and mapped near the putative cytochrome $\mathrm{c}$ biogenesis $\mathrm{ccmB}$-like mitochondrial protein. This fragment was then successfully converted into a SCAR marker, namely Mito-Foc-S001, which was found to be able to discriminate the resistance from susceptibility to Fusarium wilt disease of bananas with the discriminatory power of the new mark being $96.88 \%$. Thus, this marker can be used in banana (Musa AAA Cavendish) breeding for Fusarium wilt disease resistance.
\end{abstract}

Keywords: banana cultivars; mitochondrial genome; PCR amplifications; SCAR marker; sequencing

Abbreviatios: CTAB: cetyltrimethyl ammonium bromide; EDTA: ethylene diamine tetraacetic acid; PVP: polyvinyl pyrrolidone; RAPD: random amplified polymorphic DNA; SCAR: sequence characterized amplified region; SRAP: sequencerelated amplified polymorphism

\section{Introduction}

Banana and plantain (Musa spp.) are the fourth and the second most important food and fruit crop in the world, respectively (FAO, 2017). Banana and plantain are also the most important fresh fruit in international trade market in terms of production and consumption volume (FAO, 2013). Banana Fusarium wilt, caused by Fusarium oxysporum f. sp. cubense (Foc), is one of the most devastating diseases, especially in Asia and Africa. Foc has been classified into four physiological races according to the symptoms of different banana cultivars (Pegg et al., 1996; Bentley et al., 1998). Among them, Foc race 4 (Foc4) is the most virulent one (Sun et al., 2010). This race was first reported in Taiwan in 1969 (Sun et al., 1978) and subsequently spread to Australia, Africa and a number of Asian countries (Hwang and Ko, 2004). In China, banana Fusarium wilt caused by Foc4 has been successively reported in Guangdong, Guangxi, Fujian, Hainan provinces, including nearly all the main banana-production areas (Li et al., 2011). To date, this disease has become the key factor seriously limiting banana production in China (You et al., 2008). Since Fusarium wilt is a soil-borne disease, there has been no chemical control approach available and the only way to control it is to plant the cultivars resistant/tolerant to this pathogen (Ploetz, 2006). 
510

Conventional banana breeding is mainly hampered by the fact that most cultivars are triploid, parthenocarpy and thereafter, sterility. Biotechnological methods can contribute significantly to the genetic improvement of agronomic traits of banana cultivars, including disease resistance (Xu et al., 2011; Kovács et al., 2013; Umber et al., 2016). However, selection of disease-resistant somaclones requires large-scale field evaluations and is time-consuming (Javed et al., 2004) whereas sometimes the susceptible plants have a chance to escape detection (Burger $e t$ al., 2003) due to various other factors. Thus, development of early, reliable, and reproducible selection strategies can speed up the selection procedure and, eventually, improvement of banana production and quality (Javed and Othman, 2005).

Molecular biomarker technologies have become the powerful tools in crop improvement through their applications in germplasm characterization and fingerprinting, genetic analysis, linkage mapping, and molecular breeding. Sequence characterized amplified regions (SCARs) were originally derived from eight random amplified polymorphic DNA (RAPD) markers linked to disease resistance genes in lettuce (Paran and Michelmore, 1993). SCARs are PCR-based markers that represent single, genetically defined loci identified by PCR amplification of genomic DNA with pairs of specific oligonucleotide primers. They may contain high-copy, dispersed genomic sequences within the amplified region (Paran and Michelmore, 1993). Today, SCAR markers have been widely employed in the resistant breeding of many crops, such as wheat (Triticum aestivum L.) (Mandoulakani et al., 2015), tomato (Solanum lycopersicum L.) (Panthee and Ibrahem, 2012), sweetpotato (Ipomoea batatas) (Nakayama et al., 2012), sorghum [Sorghum bicolor (L.) Moench] (Singh et al., 2006), cotton (Gossypium hirsutum L.) (Wang et al., 2009), barley (Hordeum vulgare) (Genger et al., 2003) as well as banana (Wang et al., 2012; Cunha et al., 2015; Das et al., 2016; Silva et al., 2016).

However, all the reported SCAR markers linked to plant resistance are located in nuclear chromosomes. Mitochondria are one of the most plant cell organelles and have been suggested to play a very important role in plant defenses (Gleason et al., 2011; Laluk et al., 2011; Ambrosio et al., 2013; Qamar et al., 2015; Fuchs et al., 2016). Furthermore, mitochondrial DNA (mtDNA) is also widely used as molecular markers in the fields of systematic evolution, cytoplasmic male sterility and so on (Ji et al., 2014; Gao et al., 2015; Shu et al., 2016). However, to date, there have been no reports about the presence of plant disease resistance or susceptibility-related SCAR markers in mitochondrial genome yet. Whether SCAR markers related to plant disease susceptibility or resistance are present in mitochondrial genome remains to be determined.

In the present study, we developed a novel SCAR marker, which was located in mitochondrial genome and associated with Foc4 susceptibility of Musa AAA Cavendish, through sequence-related amplified polymorphism (SRAP)-based screening. This marker could discriminate the resistance from susceptibility to Fusarium wilt disease of bananas with the discriminatory power of the new mark being $96.88 \%$. The availability of this novel SCAR marker will provide an essential tool to diagnose Foc resistant germplasm and facilitate molecular marker-assisted selection of novel banana cultivars resistant to this pathogen.

\section{Materials and Methods}

\section{Plantmaterial}

A total of thirty-two banana (Musa AAA Cavendish) cultivars with different degrees of resistance or susceptibility to Foc4 were used in the present study and their characteristics were presented in Table 1 . The test of their resistance or susceptibility was carried out in the inoculated field for identification of resistant banana germplasm after a 3-year period (from 2012-2015) of observation and investigation.

\section{DNA extraction}

DNA was extracted by a modified cetyltrimethyl ammonium bromide (CTAB) method described by Javed et al. (2004) with modifications. In brief, fresh leaves $(0.2 \mathrm{~g})$ were ground to powder in liquid nitrogen with cross-linked polyvinyl pyrrolidone (PVP), suspended in $800 \mu \mathrm{L}$ of preheated extraction buffer [ $4 \%$ CTAB, $1.4 \mathrm{M} \mathrm{NaCl}, 20$ $\mathrm{mM}$ ethylene diamine tetraacetic acid (EDTA), $100 \mathrm{mM}$ Tris- $\mathrm{HCl}[\mathrm{pH} 8.0]$ and $1 \% 2$-mercaptoethanol at $65^{\circ} \mathrm{C}$ for $30 \mathrm{~min}$, followed by centrifugation at $12000 \mathrm{rpm}$ for 10 min. The supernatant was saved and extracted twice with equal volumes of chloroform/isoamyl alcohol (24:1). The supernatant was combined and centrifuged at $12000 \mathrm{rpm}$ for 6 min. DNA was pelleted with equal volumes of precooled isopropanol $\left(-20^{\circ} \mathrm{C}\right)$. After being rinsed with $75 \%$ pre-cooled ethanol, DNA sample was dried under vacuum and then dissolved in $50 \mu \mathrm{L}$ of TE buffer $[10 \mathrm{mM}$ Tris-Hcl ( $\mathrm{pH}$ 8.0), 1 mM EDTA, $\mathrm{pH}$ 8.0]. The DNA concentration was determined with an ultra low volume spectrometer (BioDrop $\mu$ Lite, Biochrom/UK). The concentration was adjusted to $50 \mathrm{ng} \cdot \mu \mathrm{L}^{-1}$ with $\mathrm{ddH}_{2} \mathrm{O}$ before use.

\section{Cloning and sequencing of SRAP products}

For screening the molecular markers involved in Foc4 resistance of banana, three susceptible ('Baxijiao', 'NK4-1', and 'L3-3') and four resistant cultivars ('Kangku 1', 'Nantiahuang,, 'Kangku 5', 'Nongke 1') were used as the plant materials (Table 1). One hundred pairs of primers with each primer containing the original 10 bases were synthesized and used for SRAP, which are available from Thermo Fisher (China) Co., LTD. Guangzhou Branch (Table 2).

PCR amplifications were performed according to the manufacturers' instructions and run in a Bio-Rad PCR (Bio-Rad T100, Bio-Rad, Hercules, CA, USA) with a total reaction mixture of $25 \mu \mathrm{L}$, containing $2.5 \mu \mathrm{L}$ of $10 \times$ buffer (with $\mathrm{Mg}^{2+}$ ), $2 \mu \mathrm{L}$ of $0.25 \mathrm{mM} \mathrm{dNTPs}$, reverse and inverse primers at a final concentration of $0.4 \mu \mathrm{M}, 1 \mu \mathrm{L}$ of DNA template $\left(50 \mathrm{ng} \cdot \mu \mathrm{L}^{-1}\right)$ and 1.5 unit of TaqDNA polymerase (Tiangen, Beijing, China). Reactions were programmed to an initial denaturation for $5 \mathrm{~min}$ at $94{ }^{\circ} \mathrm{C}$, followed by 5 cycles as follows: 1 min at $94^{\circ} \mathrm{C}$ denaturation, $1 \mathrm{~min}$ at $35^{\circ} \mathrm{C}$ annealing and $1 \mathrm{~min}$ at $72^{\circ} \mathrm{C}$ elongation and then by 35 cycles consisting of $1 \mathrm{~min}$ at $94^{\circ} \mathrm{C}$ denaturing, $1 \mathrm{~min}$ at $50^{\circ} \mathrm{C}$ annealing and $1 \mathrm{~min}$ at $72{ }^{\circ} \mathrm{C}$ elongation, and final elongation at $72^{\circ} \mathrm{C}$ for $8 \mathrm{~min}$. 
Table 1. The 34 banana (Musa AAA Cavendish) cultivars and their reactions to Foc 4 in the field and predicted by the SCAR marker

\begin{tabular}{|c|c|c|c|c|}
\hline Code & Cultivar & $\begin{array}{l}\text { Morbidity to Foc4 natural in the } \\
\text { field (\%) }\end{array}$ & $\begin{array}{l}\text { Resistance evaluation } \\
\text { to Foc } 4 \text { in the field }\end{array}$ & $\begin{array}{l}\text { Predicted by the } \\
\text { SCAR marker }\end{array}$ \\
\hline 1 & 'Baxijiao' & 100.0 & $\mathrm{HS}$ & S \\
\hline 2 & 'NK4-1' & 100.0 & HS & $S$ \\
\hline 3 & 'L1N2' & 80.0 & S & S \\
\hline 4 & 'L3-3' & 100.0 & HS & S \\
\hline 5 & 'WS2' & 97.1 & HS & S \\
\hline 6 & 'Nantianqing' & 41.7 & MR & $\mathrm{R}$ \\
\hline 7 & 'Dongjiao 1' & 36.0 & MR & $\mathrm{R}$ \\
\hline 8 & 'Kangku l' & 25.1 & $\mathrm{R}$ & $\mathrm{R}$ \\
\hline 9 & 'Somalia' & 100.0 & HS & S \\
\hline 10 & 'Tianbao Ai' & 100.0 & HS & S \\
\hline 11 & 'Williams' & 100.0 & HS & $S$ \\
\hline 12 & 'Longzhou Zhongba' & 100.0 & HS & S \\
\hline 13 & ‘Cuba Xiangya’ & 100.0 & HS & S \\
\hline 14 & 'G6-2’ & 26.3 & $\mathrm{R}$ & $\mathrm{R}$ \\
\hline 15 & 'Yueke 1' & 30.5 & MR & $\mathrm{R}$ \\
\hline 16 & 'Nongke 1' & 42.9 & MR & $\mathrm{R}$ \\
\hline 17 & 'Kangku 5' & 5.0 & HR & $\mathrm{R}$ \\
\hline 18 & 'Zhangxuan 8-1' & 90.0 & $S$ & S \\
\hline 19 & 'Guangdong 2' & 100.0 & HS & S \\
\hline 20 & 'Dongguan Gaoba' & 100.0 & HS & $S$ \\
\hline 21 & 'Qiwei' & 100.0 & HS & S \\
\hline 22 & 'Honghe Ai' & 100.0 & HS & S \\
\hline 23 & 'Pubei Ai' & 100.0 & HS & S \\
\hline 24 & 'Moxigexiangjiao' & 90.0 & $S$ & S \\
\hline 25 & 'Dongguan Zhongba' & 90.0 & $S$ & S \\
\hline 26 & 'Hekou Gaoba’ & 100.0 & HS & S \\
\hline 27 & 'Helanxiangjiao' & 100.0 & HS & S \\
\hline 28 & 'Beida Ai' & 90.0 & $S$ & S \\
\hline 29 & 'Nalong Zhongba' & 100.0 & HS & S \\
\hline 30 & 'Nantianhuang' & 50.0 & MR & $\mathrm{R}$ \\
\hline 31 & 'BXM51' & 34.0 & MR & $\mathrm{R}$ \\
\hline 32 & 'Ke 2’' & 55.0 & MS & $\mathrm{R}$ \\
\hline
\end{tabular}

HR: highly resistant (morbidity $\leq 10 \%)$; R: resistant $(10 \%<$ morbidity $\leq 30 \%)$;

MR: moderately resistant $(30 \%<$ morbidity $\leq 50 \%)$;

MS: moderately susceptible $(50 \%<$ morbidity $\leq 70 \%)$;

S: susceptible $(70 \%<$ morbidity $\leq 90 \%)$;

HS: highly susceptible (morbidity $>90.0 \%$ );

Foc4: Fusarium oxysporum $\mathrm{f}$. sp. cubense race 4

SCAR: sequence characterized amplified region.

Table 2. Primers for PCR and sequences of SRAP primer sets

\begin{tabular}{|c|c|c|c|}
\hline $\begin{array}{l}\text { Forward } \\
\text { primer }\end{array}$ & $\begin{array}{l}\text { Sequence } \\
\left(5^{\prime}-3^{\prime}\right)\end{array}$ & $\begin{array}{l}\text { Reverse } \\
\text { primer }\end{array}$ & $\begin{array}{l}\text { Sequence } \\
\left(5^{\prime}-3^{\prime}\right)\end{array}$ \\
\hline mel & 5'-TGAGTCCAAACCGGATA-3' & $\mathrm{eml}$ & 5'-GACTGCGTACGAATTCAA-3' \\
\hline me2 & 5'-TGAGTCCAAACCGGAGC-3' & em2 & 5'-GACTGCGTACGAATTCTG-3' \\
\hline me3 & 5'-TGAGTCCAAACCGGACC-3' & $\mathrm{em} 3$ & 5'-GACTGCGTACGAATTGAC-3' \\
\hline me4 & 5'-TGAGTCCAAACCGGACA-3' & em4 & 5'-GACTGCGTACGAATTTGA-3' \\
\hline mes & 5'-TGAGTCCAAACCGGTGC-3' & $\mathrm{em} 5$ & 5'-GACTGCGTACGAATTAAC-3' \\
\hline me6 & 5'-TGAGTCCAAACCGGAGA-3' & em6 & 5'-GACTGCGTACGAATTGCA-3' \\
\hline me7 & 5'-TGAGTCCAAACCGGACG-3' & $\mathrm{em} 7$ & 5'-GACTGCGTACGAATTGAG-3' \\
\hline me8 & 5'-TGAGTCCAAACCGGAAA-3' & em8 & 5'-GACTGCGTACGAATTGCC-3' \\
\hline me9 & 5'-TGAGTCCAAACCGGAAC-3' & em9 & 5'-GACTGCGTACGAATTTCA-3' \\
\hline mel0 & 5'-TGAGTCCAAACCGGAAT-3' & $\mathrm{em} 10$ & 5'-GACTGCGTACGAATTCAT-3' \\
\hline
\end{tabular}

SRAP: sequence-related amplified polymorphism. 
After amplification, $4 \mathrm{uL}$ of $6 \times$ loading buffer was added to the PCR amplified products. 8-10 $\mu \mathrm{L}$ of PCR products were fractionated by gel electrophoresis on $1.8 \%$ $(\mathrm{w} / \mathrm{v})$ agarose gels in $0.5 \times$ Tris-borate-EDTA (TBE) buffer ( $\mathrm{pH}$ 8.0). Gel was run at $120 \mathrm{~V}$ for $1 \mathrm{~h}$, stained with ethidium bromide, visualized on a UV transilluminator and photographed with gel imaging system (UVI FireReader, UK).

The amplified products of the linked SRAP were excised from agarose gels, and the DNA was purified by Tiangel Midi purification kit (Tiangen) according to the manufacturers' instructions followed by sending to Thermo Fisher (China) Co., LTD. Guangzhou Branch for sequencing. The purified products was amplified with BigDye Terminator v3.1 Cycle Sequencing Kit [Thermo Fisher Scientific, Applied Biosystems, Foster City, CA, USA], and the PCR products were purified using the MagBind $^{\circ}$ RxnPure Plus (OmegaBiotek, Norcross, GA, USA). Finally, the products were sequenced using a 3730xl DNA analyzer [Thermo Fisher Scientific (Applied Biosystems)].

\section{SCAR design and analysis}

The sequence obtained from SRAP was analyzed by MAGE6.0 Software, followed by blasting in NCBI and http://banana-genome-hub.southgreen.fr/blast. Four pairs of primers for SCAR were designed with $\mathrm{NCBI} /$ primerBLAST based on the sequence. They were also synthesized by Thermo Fisher (China) Co., LTD. Guangzhou Branch (Table 3). To screen and develop the SCAR marker, DNA samples isolated from three resistant cultivars ('Nantianqing', 'Dongjiao 1', and 'Kangku 1') and five susceptible ones ('Baxijiao', 'NK4-1', 'L1N2', 'L3-3', and 'WS2') were used as the templates, respectively. The optimized PCR reaction mixture was $20 \mu \mathrm{L}$ in total volume, containing $2 \mu \mathrm{L}$ of $10 \times$ buffer (with $\mathrm{Mg}^{2+}$ ), $2 \mu \mathrm{L}$ of dNTPs $(2.5 \mathrm{mM}), 1 \mu \mathrm{L}$ of reverse and inverse primers $(10 \mu \mathrm{M}), 1 \mu \mathrm{L}$ of DNA ( $\left.50 \mathrm{ng} . \mu \mathrm{L}^{-1}\right)$ and 1.0 unit of TaqDNA polymerase. Reactions were programmed to an initial denaturation at 94 ${ }^{\circ} \mathrm{C}$ for $5 \mathrm{~min}$, and then to 35 cycles as follows: 30 s at $94^{\circ} \mathrm{C}$ denaturation, $30 \mathrm{~s}$ at $60{ }^{\circ} \mathrm{C}$ annealing and $30 \mathrm{~s}$ at $72{ }^{\circ} \mathrm{C}$ elongation. The final elongation step was prolonged to 7 $\min$ at $72^{\circ} \mathrm{C}$.

PCR products were fractionated by gel electrophoresis on $1.2 \%(\mathrm{w} / \mathrm{v})$ agarose gels in $0.5 \times \mathrm{TBE}[\mathrm{pH} 8.0])$ buffer. Gel was run at $110 \mathrm{~V}$ for $25 \mathrm{~min}$, stained with ethidium bromide, visualized on a UV transilluminator and photographed with gel imaging system.

\section{Validation of the SCAR marker}

The linked SCAR marker obtained in the present study was validated with another 24 banana cultivars with different degrees of resistance to Foc4 (cultivars No. 9-32 in Table 1), including the two cultivars originally used as the templates of SRAP. PCR reaction system was referred to the method described in 1.4.

\section{Results}

\section{DNA quality}

The quality of the extracted DNA was checked with BioDrop $\mu$ Lite (Biochrom/UK). The concentration of DNA samples was between 80 and $150 \mathrm{ng} \cdot \mu \mathrm{L}^{-1}$, the $\mathrm{OD}_{260} / \mathrm{OD}_{280}$ ratios of all the samples were in the range of 1.8 to 2.0 , indicating that the quality is good enough to be used for further experiment.

Screening of SRAP molecular markers involved in disease resistance

As shown in Fig. 1, a special band of 839 bp was amplified from DNA templates derived from three susceptible cultivars ('Baxijiao', 'NK4-1', and 'L3-3') by PCR with primer me6-em1 out of 100 pairs of SRAP primers tested. However, it was absent in all the resistant cultivars.

\section{Development of a SCAR marker involved in banana} resistance to Foc4

The PCR amplified products were collected from cultivars 'Baxijiao', 'NK4-1', and 'L3-3'. The qualities and concentrations were good enough. These products were sequenced and compared with that of MAGE6.0. The result showed that their sequences were exactly the same.

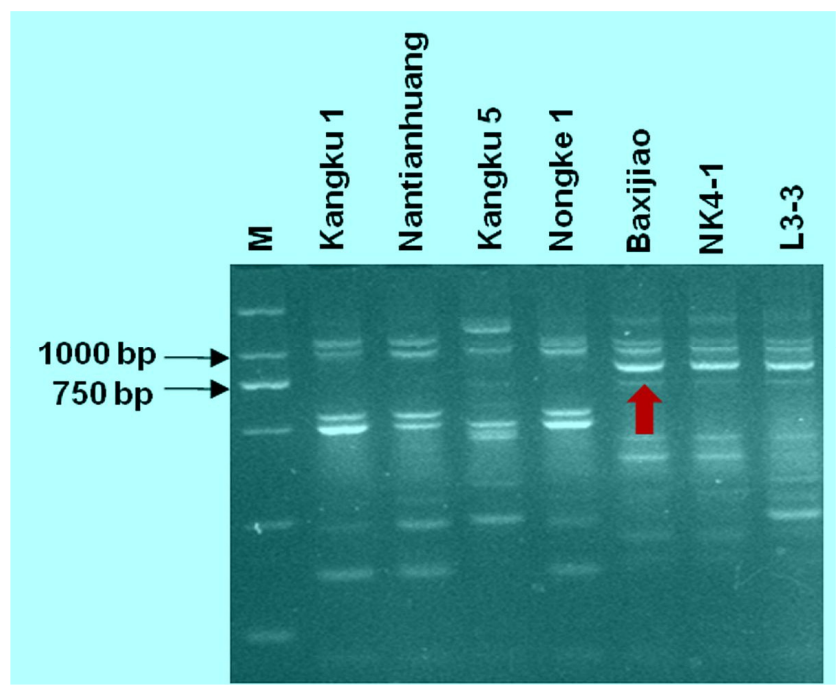

Fig. 1. The PCR products amplified with SRAP primer set (me6-em1) in 7 banana (Musa AAA Cavendish) cultivars either resistant or susceptible to Foc4. M: 2000 bp marker; lanes 1-4: resistant cultivars; lanes 5-76: susceptible cultivars; Foc4: Fusarium oxysporum f. sp. cubense race 4; SRAP: sequence-related amplified polymorphism. Red arrow indicates the specific band of $829 \mathrm{bp}$

Table 3. Primers for PCR and sequences of SCAR primer sets

\begin{tabular}{cccc}
\hline Primer set & Sequence of primer(5'-3') & Tm & Product length (bp) \\
\hline SC1/SC2 & CTCGCCGACACCTTACTTGA/AGGAGAGTCCAGCTCCAGTT & 60 & 324 \\
SC3/SC4 & CTTATTGCTTCCTCGCCGAC/CAGTAGGGGTCTCGTTGCTT & 59 & 293 \\
SC5/SC6 & CTCGCCGACACCTTACTTGAT/GGGGTCTCGTTGCTTGTCTC & $60-61$ & 59 \\
SC7/SC8 & TCGCCGACACCTTACTTGAT/ACAGTAGGGGTCTCGTTGCT & 277 \\
\hline
\end{tabular}

SCAR: sequence characterized amplified region 
No assignment to a particular chromosome or resemblance with known resistance or susceptibility genes was revealed when blasted this fragment in NCBI. However, when being compared with Banana Genome Hub database (bttp://banana-genome-hub.southgreen.fr/blast), it showed a $99.64 \%$ similarity to a fragment located in mito 4 of the $M$. acuminata spp. malaccensis accession Pahang $(2 n=22)$ genome (start from the third nucleotide). This fragment is located between nucleotides 145, 680 and 146, 506 and mapped near the putative cytochrome $\mathrm{c}$ biogenesis $\mathrm{ccmB}$ like mitochondrial protein.

To develop SCAR markers, we selected four pairs of primers presented in Table 3 to amplify the PCR products from 8 banana cultivars with different degrees of resistance to Foc4.

Fig. 2 showed that a single and clear band of 324 bp was amplified with primers SC1 and SC2 and appeared only in five susceptible cultivars ('Baxijiao', 'NK4-1', 'L1N2', 'L3-3', and 'WS2') but not in the three resistant ones ('Nantianqing', 'Dongiiao 1', and 'Kangku 1'). This fragment is located in the position from 216 to $539 \mathrm{bp}$ of the original SRAP band (located between the mitochondrial genome nucleotides 145,894 and 146, 217). The quality of the band was good enough to serve as a
SCAR marker and thus, was considered a suitable candidate for the development of the SCAR marker, and finally selected. On the other hand, some other special bands were also obtained with the other three pairs of primers, which also could distinguish the resistant cultivars from the susceptible ones; however, their qualities were not good enough to be used as a SCAR marker (data not shown).

\section{Validation of the SCAR marker}

To validate the SCAR marker obtained, we used 24 banana cultivars with different degrees of resistance, including the two cultivars originally used as the templates of SRAP. The results from the PCR amplification with primers SC1 and SC2 indicated a high degree of specificity of this SCAR marker (namely Mito-Foc-S001), because a 324 bp band appeared in all the 17 susceptible cultivars tested ('Somalixiangjiao', 'Tianbao Ai', 'Williams', 'Longzhou Zhongba', 'Cuba Xiangya', 'Zhangxuan 8-1', 'Guangdong 2', 'Dongguan Gaoba', 'Qiwei', 'Honghe Ai', 'Pubei Ai', 'Moxigexiangjiao', 'Dongguan Zhongba', 'Hekou Gaoba', 'Helanxiangjiao', 'Beida Ai', and 'Nalong Zhongba') but was absent in the 6 resistant ones ('G6-2', 'Yueke 1', 'Nongke 1', 'Kangku 5', 'Nantianhuang', and 'BXM51') and 1 susceptible one ('Ke 2') (Fig. 3).

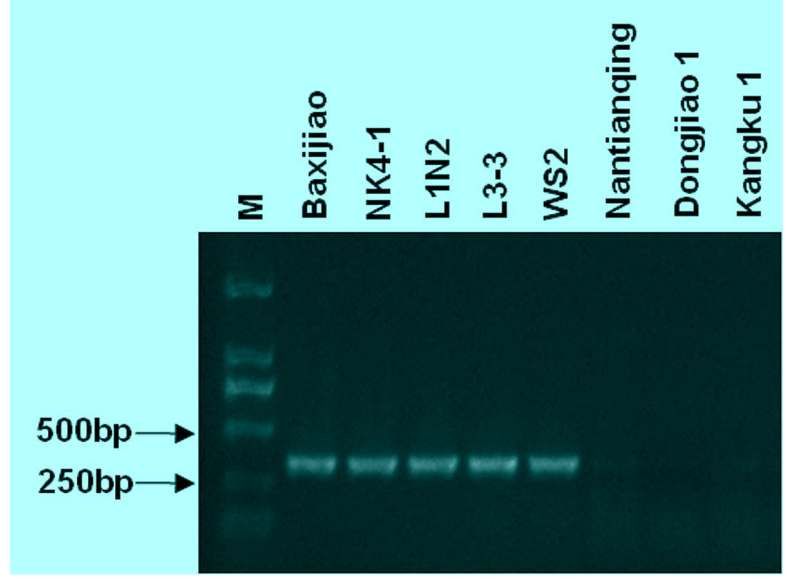

Fig. 2. The PCR products amplified with DNA templates derived from eight banana (Musa spp. AAA Cavendish) cultivars with SCAR primer set (SC1-SC2) either resistant or susceptible to Foc4. M: 2000 bp marker; lanes 1-5: susceptible cultivars; lanes 6-8: resistant cultivars; Foc4: Fusarium oxysporum f. sp. cubense race 4; SCAR: sequence characterized amplified region

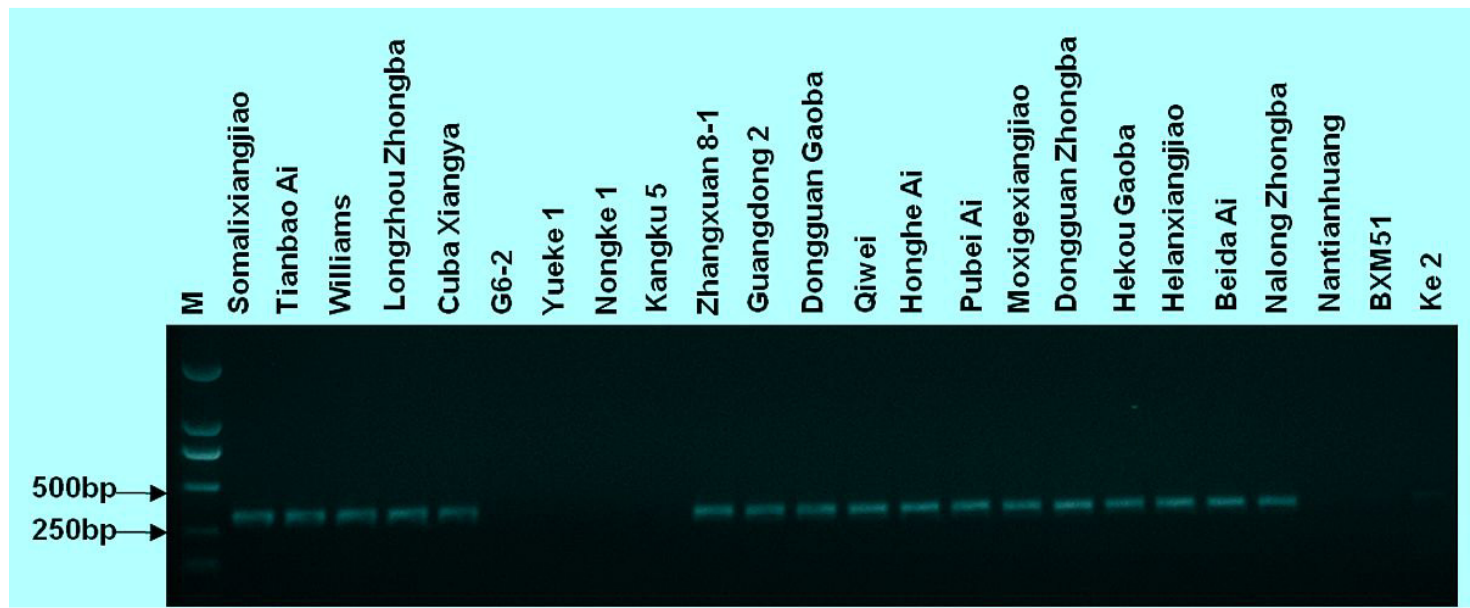

Fig. 3. Analysis of the SCAR marker in 24 banana (Musa spp. AAA Cavendish) cultivars either resistant or susceptible to Foc4. M: 2000 bp marker; lanes 1-5 and 10-21: susceptible cultivars; lanes 6-9 and 22-24: resistant cultivars; Foc4: Fusarium oxysporum f. sp. cubense race 4; SCAR: sequence characterized amplified region 
514

The PCR amplification results of all 32 test banana cultivars, was in agreement with the resistance evaluation to Foc4 in the field for 31 out of 32 , which indicates a discriminatory power of $96.88 \%$ (Figs. 2 and 3 ). This SCAR marker is reliable although there is a minimal error.

\section{Discussion}

As mentioned above, banana Fusarium wilt is one of the most devastating diseases found in a large majority of the banana-producing regions in the world except the Mediterranean, Melanesia, Somalia, and some islands in the South Pacific (Ploetz, 2006). To date, no methods for efficient control of this disease are available. The best way to control this disease is to plant the resistant cultivars. Identification of molecular markers linked to disease resistance is an excellent alternative to enable banana breeders to make marker-assisted selection for disease resistance without challenging the host with the pathogen. Javed and Othman (2005) studied the resistance of Musa acuminata to Fusarium oxysporum using the technique of RAPD. The SCAR markers associated with the resistance to this disease was first reported by Wang et al. (2012). They detected the resistance of clones from 'Williams' (Musa spp. AAA) using two SCAR markers, namely ScaU1001 and ScaS0901, which were amplified in 'Gold finger' (Musa spp. $A A A B)$ and one clone from 'Williams'. These SCAR markers could not be detected in 5 susceptible cultivars tested. Recently, Cunha et al. (2015) generated a SCAR marker from RAPD markers which could identify susceptibility to Fusarium oxysporum f. sp. cubense for some banana cultivars belonging deferent genotypes in South Brazil. They validated this SCAR marker on 28 banana cultivars resistant or susceptible to infection by Foc. Their result showed that this new marker could discriminate two contrasting groups from each other with the discriminatory power of $93 \%$.

In the present study, we identified a novel and specific SCAR marker from 100 pairs of SRAP primers associated with susceptibility to Foc4. We tested the specificity of this marker against a total of 32 banana cultivars exhibiting different degrees of resistance or susceptibility to Foc4. Nine resistant cultivars including the most resistant germplasm in China and a few from other countries and 23 susceptible cultivars including the main cultivars grown in China and some other countries as well as a number of the local cultivars in China were purposely selected, respectively. The new SCAR marker, namely Mito-Foc-S001, could distinguish the resistant group from the susceptible one with the discriminatory power of $96.88 \%$. The sequence of PCR product from primers SC1 and SC2 had high homology with a fragment in mito 4 of banana, indicating that this SRAP-based SCAR marker is a gene located in the mitochondrial genome instead of in the nuclear chromosomes. Though no a particular chromosome or resemblance with known resistance or susceptibility genes have been assigned with the fragment identified in this study, further developments may enable us to reveal similarities of this sequence to the known genes.

Mitochondria are semi-autonomous organelles that possess their own genomes and are able to synthesize a small number of proteins essential for the functions of mitochondrial respiratory chain. They are the main fuel stations of eukaryotic cells because they are a major source of ATP. In addition, they are vital for cellular homeostasis, participating in diverse metabolic pathways, calcium signalling and reactive oxygen species buffering or production. These functions link mitochondrial activities to the environment and with other cellular compartments such as chloroplast (Welchen et al., 2014). Many earlier reports revealed that mitochondria contributed substantially to responses to plant stress and defense responses (Gleason et al., 2011; Laluk et al., 2011; Ambrosio et al., 2013; Qamar et al., 2015; Fuchs et al., 2016) and/or play a fundamental role in innate immunity signalling (Vellosillo et al., 2013). Defects in mitochondrial functions could increase susceptibility of plants to pathogens (Pu et al., 2016). Thus, it was suggested that the SCAR marker obtained in the present study also likely plays a very important role in banana susceptibility to Foc4. However, no assignment to a particular chromosome or resemblance with known resistance of susceptibility genes was revealed. The information about this novel marker is quite limited. Further work should be focused on acquiring these pieces of information and investigating the specific functions of mitochondrial genes in banana defenses.

\section{Conclusions}

Our results demonstrate that the SCAR marker MitoFoc-S001, could discriminate the resistance from susceptibility to Fusarium wilt disease of bananas with the discriminatory power of the new marker being $96.88 \%$. The application of the marker is simple and efficient, and has a great advantage for the screening of large number of banana individuals, since only DNA extracted and a simple PCR are required. Thus, this marker can be used in banana (Musa AAA Cavendish) breeding for Fusarium wilt disease resistance.

\section{Acknowledgements}

We thank Dr. Rui Xia for helpful discussions and input. This work was supported by Social Development Science and Technology Project of Dongguan (No. 2013108101043), Natural Science Foundation of Guangdong Province (2015A030313421) and Key Technologies Research and Development Program of Guangdong Province (2014A020208111).

The research was conducted in Dongguan Banana and Vegetable Institute, Dongguan 523061, China.

\section{References}

Ambrosio AB, do Nascimento LC, Oliveira BV, Teixeira PJPL, Tiburcio RA, Thomazella DPT, ... Cabrera OG (2013). Global analyses of Ceratooystis cacaofunesta mitochondria: from genome to proteome. BMC Genomics 14:91.

Bentley S, Pegg KG, Moore NY, Davis RD, Buddenhagen IW (1998). Genetic variation among vegetative compatibility groups of Fusarium oxysporum f. sp. cubense analyzed by DNA fingerprinting. 
Phytopathology 88(12):1283-1293.

Burger Y, Katzir N, Tzuri G, Portnoy V, Saar U, Shriber S, ... Cohen R (2003). Variation in the response of melon genotypes to Fusarium oxysporum f.sp. melonis race 1 determined by inoculation tests and molecular markers. Plant Pathology 52:204211.

Cunha CMS, Hinz RH, Pereira A, Tcacenco FA, Paulino EC, Stadnik MJ (2015). A SCAR marker for identifying susceptibility to Fusarium oxysporum f.sp. cubense in banana. Scientia Horticulturae 191:108-112.

Das T, Mondal S, Mishra DK, Bhattacharyya S (2016). Development of SCAR marker for screening Sigatoka-leafspot resistance in banana genotypes. Indian Journal of Genetics and Plant Breeding 76(1):69-74.

FAO (2013). Food and Agricultural Organization. Retrieved 2018 February 6 from www.fao.org/production/faostat.

FAO (2017). Food and Agricultural Organization. Retrieved 2018 February 6 from www.fao.org/production/faostat.

Fuchs R, Kopischke M, Klapprodt C, Hause G, Meyer AJ, Schwarzlander M, ... Lipka V (2016). Immobilized subpopulations of leaf epidermal mitochondria mediate penetration2-dependent pathogen entry control in Arabidopsis. Plant Cell 28:130-145.

Gao LM, Chen YQ, Huo YM, Dong F, Yang YY, Kong SP, ... Wu X (2015). Development of SCAR markers to distinguish male-sterile and normal cytoplasm in bunching onion (Allium fistulosum L.). Journal of Horticultural Science \& Biotechnology 90:57-62.

Genger RK, Brown AHD, Knogge W, Nesbitt K, Burdon JJ (2003). Development of SCAR markers linked to a scald resistance genederived from wild barley. Euphytica 134(2):149-159.

Gleason C, Huang SB, Thatcher LF, Foley RC, Anderson CR, Carroll AJ, ... Singh KB (2011). Mitochondrial complex II has a key role in mitochondrial-derived reactive oxygen species influence on plant stress gene regulation and defense. Proceedings of the National Academy of Sciences of the United States of America 108(26):10768-10773.

Hwang SC, Ko WH (2004). Cavendish banana cultivars resistant to Fusarium wilt acquired through somaclonal variation in Taiwan. Plant Disease 88(6):580-588.

Javed MA, Chai M, Othman RY (2004). Study of resistance of Musa acuminata to Fusarium oxysporum using RAPD markers. Biologia Plantarum 48(4):93-99.

Javed MA, Othman RY (2005). Characterization of Fusarium wilt-resistant and Fusarium wilt-susceptible somaclones of banana cultivar Rastali (Musa $\mathrm{AAB}$ ) by random amplified polymorphic DNA and retrotransposon markers. Plant Molecular Biology Reporter 23(3):241249.

JiJJ, Huang W, Yin YX, Li Z, GongZH (2014). Development of a SCAR marker for early identification of S-cytoplasm based on mitochondrial SRAP analysis in pepper (Capsicum annuum L.). Molecular Breeding 33(3):679-690.

Kovács G, Sági L, Jacon G, Arinaitwe G, Busogoro JP, Thiry E, ... Remy S (2013). Expression of a rice chitinase gene in transgenic banana ('Gros Michel', AAA genome group) confers resistance to black leaf streak disease. Transgenic Research 22(1):117-130.

Laluk K, AbuQamar S, Mengist T (2011). The Arabidopsis mitochondrialocalized pentatricopeptide repeat protein PGN functions in defense against necrotrophic fungi and abiotic stress tolerance. Plant Physiology
156(4):2053-2068.

Li MH, Yang B, Leng Y, Chao CP, Liu J M, He ZF, Jiang ZD, Zhong S (2011). Molecular characterization of Fusarium oxysporum $\mathrm{f}$. sp. cubense race 1 and 4 isolates from Taiwan and Southern China. Canadian Journal of Plant Pathology33(2):168-178.

Mandoulakani BA, Yaniv E, Kalendar R, Raats D, Bariana HS, Bihamta MR, Schulman AH (2015). Development of IRAP-and REMAPderived SCAR markers for marker-assisted selection of the stripe rust resistance gene $\operatorname{Yr} 15$ derived from wild emmer wheat. Theoretical and AppliedGenetics 128:211-219.

Nakayama H, Tanaka M, Takahata Y, Matsui K, Iwahori H, Sano Z, Yoshinaga M (2012). Development of AFLP-derived SCAR markers associated with resistance to two races of southern root-knot nematode in sweet potato. Euphytica 188(2):175-185.

PantheeDR, Ibrahem R (2013). New molecular markers associated with the $\mathrm{Sw}-5$ gene conferring resistance to tomato spotted wilt virus in tomato. Journal of Pomology \& Horticultural Science 88(2):129-134.

Paran I, Michelmore RW (1993). Development of reliable PCR-based markers linked to downy mildew resistance genes in lettuce. Theoretical and Applied Genetics 85:985-993.

Pegg KG, Moore NY, Bentley S (1996). Fusarium wilt of banana in Australia: a review. Crop\& PastureScience 47(5):637-650.

Ploetz RC (2006). Fusarium wilt of banana is caused by several pathogens referred to as Fusarium oxysporum f. sp. cubense. Phytopathology 96(6):653-656.

Pu XJ, Li YN, Wei LJ, Xi DH, Lin HH (2016). Mitochondrial energydissipation pathway and cellular redox disruption compromises Arabidopsis resistance to turnip crinkle virus infection. Biochemical and Biophysical Research Communications 473(2):421-427.

Qamar A, Mysore KS, Senthil-Kumar M (2015). Role of proline and pyrroline-5-carboxylate metabolism in plant defense against invading pathogens. Frontiers in Plant Science 6:503.

Shu JS, Liu YM, Li ZS, Zhang LL, Fang ZY, Yang L M, ... Lv HH (2016). Detection of the diversity of cytoplasmic male sterility sources in broccoli (Brassica oleracea var. Italica) using mitochondrial markers. Frontiers in Plant Science 7:927.

Silva PRO, de Jesus ON, Bragança CAD, Haddad F, Amorim EP, Ferreira CF (2016). Development of a thematic collection of Musa spp. accessions using SCAR markers for preventive breeding against Fusarium oxysporum f. sp. cubense tropical race 4. Genetics and Molecular Research 15(1):1-8.

Singh M, Chaudhary K, Singal HR, Magill CW, Boora KS (2006). Identification and characterization of RAPD and SCAR markers linked to anthracnose resistance gene in sorghum [Sorghum bicolor (L.) Moench].Euphytica 149:179-187.

Sun DQ, Hu YL, ZhangLB, Mo YW, XieJH (2010). Cloning and analysis of Fusarium wilt resistance gene analogs in 'Goldfinger' banana. Molecular Pathogens 1(1):1-7.

Sun EJ, Su HJ, Ko WH(1978). Identification of Fusarium oxysporum $\mathrm{f}$. sp. cubense race 4 from soil or host tissue by cultural characters. Phytopathology68(11):1672-1673.

Umber M, Pichaut JP, Farinas B, Laboureau N, Janzac B, Plaisir-Pineau K, ... Teycheney PY (2016). Marker-assisted breeding of Musa balbisiana 
516

genitors devoid of infectious endogenous banana streak virus sequences. Molecular Breeding 36(6):1-11.

Vellosillo T, Aguilera V, Marcos R, Bartsch M, Vicente J, Cascon T, ... Castresana C (2013). Defense activated by 9-lipoxygenase-derived oxylipins requires specific mitochondrial proteins. Plant Physiology 161:617-627.

Wang PZ, Su L, Qin L, Hu B, Guo WZ, Zhang TZ (2009). Identification and molecular mapping of a Fusarium wilt resistant gene in upland cotton. Theoretical and Applied Genetics 119:733-739.

Wang W, Hu Y, Sun D (2012). Identification and evaluation of two diagnostic markers linked to Fusarium wilt resistance (race 4) in banana (Musa spp.). Molecular Biology Reports 39:451-459.
Welchen E, García L, Mansilla N, Gonzalez DH (2014). Coordination of plant mitochondrial biogenesis: keeping pace with cellular requirements. Frontiers in Plant Science 4:551.

Xu CX, Xiao J, He JG, Hu GB, Chen HB (2011). The effect of Ethylmethane sulphomate (EMS) and sodiumm azide on plant regeneration capacity of an embryogenic cell suspension of 'Yueyoukang 1' (Musa AAA), a banana cultivar resistant to Fusarium wilt. Acta Horticulturae 897:301-302.

You CP, Liu R, Xiao AP, Liu KQ, Liang Y, Chen YX (2008). Colonization of antagonistic bacterium bio-d5 against banana Fusarium wilt in the roots of banana. Journal of Huazhong Agricultural University 27(3):363-366. 